\title{
Encontros com a deficiência na universidade: deslocando o capacitismo em oficinas de formação inventiva
}

\author{
Disability meetings at the university: \\ shifting ableism in inventive learning workshops
}

Virgínia Kastrup; Laura Pozzana

Universidade Federal do Rio de Janeiro

\section{RESUMO:}

O ingresso de alunos com deficiência nas universidades públicas pelo sistema de cotas foi estabelecido com a lei 13.409 e desde 2018 a Universidade Federal do Rio de Janeiro (UFRJ) vem recebendo esses estudantes. Para além do desenvolvimento de dispositivos pedagógicos que garantam a acessibilidade desses alunos, coloca-se o problema das relações com professores, bem como entre alunos com e sem deficiência. Um dos problemas é a presença do capacitismo, que se manifesta em atitudes preconceituosas e práticas de opressão em relação às pessoas com deficiência. Uma formação universitária fundada na aquisição de competências e habilidades pode concorrer para que a política cognitiva capacitista seja perpetuada e mesmo acirrada. $\mathrm{O}$ conceito de formação inventiva (DIAS, 2011;2012) vai contra a lógica da capacitação e visa produzir outras políticas de cognição por meio de diferentes estratégias e dispositivos de formação. O objetivo do artigo é analisar a experiência de estudantes de iniciação científica e estagiárias em oficinas de formação inventiva no contexto de projetos de pesquisa-intervenção e de extensão com pessoas com deficiência. O estudo utiliza o método da cartografia (DELEUZE, GUATTARI, 1995; ROLNIK, 2006; PASSOS, KASTRUP e ESCÓSSIA, 2009; PASSOS, KASTRUP e TEDESCO, 2014) e analisa diários de campo, com ênfase na narrativa de encontros dos estudantes com pessoas com deficiência. $\mathrm{O}$ estudo identifica experiências de problematização da imagem da deficiência como incapacidade, analisa o papel do corpo aprendiz e das experiências multissensoriais em oficinas de formação inventiva, indicando possíveis deslocamentos na política cognitiva capacitista.

Palavras-chave: deficiência; política cognitiva; capacitismo

\section{ABSTRACT:}

The entry of students with disabilities into public universities through the quota system was established by Law 13.409 and since 2018 the Federal University of Rio de Janeiro (UFRJ) has been receiving these students. In addition to the development of pedagogical devices that guarantee the accessibility of these students, are also subject of concern the relations to teachers, as well as between students with and without disabilities. One of the problems is the presence of ableism, which manifests itself by acts of prejudice and practices of oppression towards people with disabilities. A higher education based only on acquisition of competences and skills can contribute to perpetuate and even reinforce a cognitive politics rooted in ableism.

The concept of inventive learning (DIAS, 2011; 2012) goes against this ableist logic and aims to produce other cognitive politics through different learning strategies and 
devices. The aim of the article is to analyze the experience of undergraduate students and interns in inventive learning workshops realized in the context of researchintervention and extension projects with people with disabilities. Through the cartography method (DELEUZE, GUATTARI, 1995; ROLNIK, 2006; PASSOS, KASTRUP e ESCÓSSIA, 2009; PASSOS, KASTRUP e TEDESCO, 2014) this study analyzes diary-based fieldnotes with an emphasis on the narrative of students' encounters with disability. The paper identifies experiences in which the image of disability as incapacity are problematized, and also analyzes the role of the apprentice body and of the multisensory experiences in inventive learning workshops, indicating possible shifts in the cognitive politics rooted in ableism.

Key-words: disability; cognitive politics; ableism

DOI: 10.12957/mnemosine.2020.52679

A presença de estudantes com deficiência na universidade pública tem ganhado espaço e importância nos últimos anos. Desde 2018, a Universidade Federal do Rio de Janeiro (UFRJ) vem adotando a política de cotas para estudantes com deficiência (Lei 13.409). Essa política tem forçado a comunidade acadêmica a refletir sobre os temas da inclusão, da acessibilidade e da deficiência. Embora não seja nova a presença de estudantes com deficiência na universidade, o aumento significativo deste número e a institucionalização do acesso aos cursos de graduação deu uma importante visibilidade ao tema, convocando a uma discussão acerca de seu papel na formação de todos os estudantes e à produção de conhecimento crítico neste domínio (KASTRUP, 2018).

O primeiro e mais evidente desafio é criar condições para que estes alunos consigam estudar e se formar. Isto força professores e gestores a pensar na criação de estratégias e dispositivos de acessibilidade para que o aluno assista aulas, estude, faça provas, trabalhos e estágio e tenha sua iniciação em atividades de pesquisa e extensão, como todos os alunos. De saída, é preciso identificar as necessidades específicas de cada tipo de deficiência. Alunos com deficiência física têm necessidade de rampas, elevadores, banheiros e mesas adaptadas; alunos com deficiência auditiva que utilizam língua de sinais dependem de intérprete de libras e aqueles que fazem leitura labial precisam, no mínimo, de um lugar na frente da sala de aula e fala pausada e frontal dos professores; para alunos com deficiência visual, um lugar na frente, textos disponíveis em formato digital acessível, uso de notebook e provas orais são algumas das estratégias e dispositivos de acessibilidade. A lista está longe de ser exaustiva. Dada a singularidade de cada aluno com deficiência, só eles poderão dizer quais as estratégias e dispositivos que podem garantir sua formação universitária. 
O problema da acessibilidade na universidade não concerne apenas aos alunos com deficiência, mas requer o envolvimento de professores, gestores, funcionários técnico-administrativos e da universidade como um todo. É também importante sublinhar que o problema da acessibilidade possui diversas dimensões e nuances, que vão bem além das questões pedagógicas e da sala de aula. Não é demais lembrar as imensas barreiras enfrentadas no deslocamento na cidade e no transporte público. No campus, existem problemas de acesso a bandejões, lanchonetes e cafés. Há também todo um campo micropolítico de tensões que emergem nas relações com professores e diversas vezes com alunos ditos sem deficiência. Já equivocando esta dicotomia, podemos perceber que uma das deficiências dos alunos ditos sem deficiência é, muitas vezes, não conseguir lidar com alunos com deficiência, sem que o capacitismo entre em cena.

Segundo Anahí Guedes de Mello (2016) o capacitismo reúne um conjunto de atitudes preconceituosas que hierarquizam pessoas em função da adequação de seus corpos a um padrão de perfeição, beleza e capacidade funcional. Traduzido do inglês ableism, o neologismo capacitismo busca dar visibilidade tanto a uma forma peculiar de opressão quanto à vida das pessoas com deficiência. Na base do capacitismo existe uma corponormatividade compulsória. Propomos falar de política cognitiva capacitista para nomear um modo de relação com as pessoas com deficiência marcado pelo preconceito e pela desigualdade, mas também pelo desinteresse e pela pouca atenção dada a elas. A referência ao desinteresse e à pouca atenção se aplica tanto ao conhecimento da singularidade de cada uma dessas pessoas quanto aos saberes que se articulam em torno de seu modo de conhecer e estar no mundo. Política cognitiva é um modo de relação com o mundo, com os outros, consigo mesmo e com a própria atividade de conhecimento (KASTRUP, 2007; KASTRUP, TEDESCO e PASSOS, 2008). O conceito aponta que o problema da cognição não se restringe a modelos teóricos. Não engendra questões apenas epistemológicas, mas também políticas. Políticas cognitivas são produzidas e produzem modos de estar no mundo, de estabelecer relação consigo e com os outros. Enfim, todo conhecer traz consigo uma posição no mundo, uma atitude, um ethos.

A política cognitiva capacitista é uma das versões da política cognitiva da representação, que tem como pressupostos a preexistência do sujeito e do objeto. A cognição representa, ou seja, reconhece algo previamente dado. Não há espaço para 
invenção de subjetividades e atualização de novas virtualidades dos objetos (KASTRUP, 2018). A versão capacitista da política da representação parte de supostas capacidades das pessoas sem deficiência, consideradas "normais", e deduz supostas limitações nas capacidades das pessoas com deficiência, então consideradas incapazes e inferiores. Em função da inadequação de seus corpos à corponormatividade, as relações restam marcadas pela desigualdade. O entendimento do capacitismo como política cognitiva visa ressaltar que este é mais do que um conjunto de ideias e crenças equivocadas, mas se caracteriza por práticas cognitivas de opressão, discriminação, interdição e atitudes de desinteresse que são tão enraizadas em nós, que se confundem com uma atitude natural.

Embora o capacitismo não comece na universidade, a política cognitiva capacitista está bastante presente nesses espaços, muitas vezes marcando de maneira implícita e silenciosa as práticas cotidianas de professores e estudantes. Uma formação universitária baseada na transmissão de informações e na aquisição de competências e habilidades concorre para que esta política seja perpetuada e mesmo acirrada.

Por sua vez, a política cognitiva da invenção configura outro modo de estar no mundo. Sujeito e objeto (no caso, um outro sujeito) não são dados previamente, mas efeitos de práticas concretas. O conhecimento não é uma experiência de reconhecimento, onde a percepção comunga com a memória. Conhecer envolve a abertura da atenção ao presente e inclui a perturbação do saber anterior, instalando frestas e bifurcações. Conhecer coloca problemas, força a pensar, acionando processos de invenção de si e do mundo (KASTRUP, 2007). Insistimos que não se chega a uma política cognitiva da invenção por transmissão de informação ou por adesão a modelos teóricos, mas por práticas cognitivas concretas, onde os processos de aprendizagem inventiva ganham lugar de destaque.

O conceito de formação inventiva (DIAS, 2011; 2012) vai na contramão da concepção de formação baseada na aquisição de habilidades e competências. Segundo Rosimeri Dias, "os processos de formação não podem ser reduzidos à aquisição de conhecimentos técnico-científicos, à transmissão de conteúdo ou informações visando mudança comportamental, a aplicação de técnicas e de teorias" (DIAS, 2012: 29). O conceito alerta para o perigo de reduzir o conhecimento a um produto a ser consumido. Chama atenção ainda para não reduzir o processo da formação ao desenvolvimento da capacidade de solucionar problemas e tampouco colocar a ênfase na avaliação dos resultados. A formação inventiva ressalta a importância de aprender a problematizar, 
de colocar novos problemas. Em síntese, afirma um "princípio ético-estético-político que distingue formar e capacitar, em que o processo de formação não se separa do modo de fazê-la; a matéria prima é, então, uma política de cognição que se desvia da lógica da capacitação e investe na experiência compartilhada entre formadores e formandos (DIAS, 2012: 29). É nesta medida que ela vai na contramão da política cognitiva capacitista.

A formação inventiva não segue regras, cartilhas e tampouco oferece procedimentos pedagógicos prontos. Ao contrário, ela suscita o desejo de criar, experimentar modos de ensinar e modos de formação múltiplos e singulares. Neste contexto, as oficinas de formação inventiva visam problematizar a política cognitiva capacitista e outras barreiras micropolíticas que atravessam as relações universitárias, concorrendo para sua explicitação, crítica e transformação (POZZANA e KASTRUP, 2015; 2019).

O objetivo deste estudo é analisar a experiência de estudantes de iniciação científica e estagiárias em projetos de pesquisa-intervenção e de extensão com pessoas com deficiência. Os projetos de pesquisa-intervenção Acessibilidade estética: cognição inventiva, atenção conjunta e ações afirmativas (CNPq), Aspectos cognitivos da Orientação e Mobilidade com pessoas com deficiência visual: em busca do movimento sensivel e vital (CAPES/FAPERJ) e o projeto de extensão Acessando uns aos outros foram desenvolvidos pelo NUCC - Núcleo de Pesquisa Cognição e Coletivos entre 2012 e 2019 no Instituto de Psicologia da UFRJ. Foi utilizado o método da cartografia (DELEUZE e GUATTARI, 1995; ROLNIK, 2006; PASSOS, KASTRUP e ESCÓSSIA 2009; PASSOS, KASTRUP e TEDESCO, 2014) e foram analisados diários de campo com relatos cartográficos produzidos pelos estudantes, com ênfase na narrativa de encontros com pessoas com deficiência. O estudo identifica experiências de problematização da imagem da deficiência como incapacidade e analisa o papel do corpo aprendiz e das experiências multissensoriais em oficinas de formação inventiva, indicando possíveis deslocamentos na política cognitiva capacitista.

\section{Experiências de problematização}

O projeto de pesquisa Acessibilidade estética para pessoas com deficiência visual: cognição inventiva, atenção conjunta e ações afirmativas tem como objetivo analisar a potência das práticas artísticas para a criação de uma política de 
acessibilidade na universidade. Num primeiro momento volta-se para a relação entre pessoas com deficiência visual e pessoas videntes e, num segundo momento, inclui as demais deficiências. Realiza Encontros Estéticos que oferecem oficinas de práticas artísticas e/ou de sensibilização, visando o encontro da diversidade de corpos, a partilha de experiências e a aprendizagem coletiva.

No I Encontro Estético foi realizada uma Oficina de DanceAbility conduzida por Sofia Giliberti, professora e dança-movimento terapeuta (DMT), visando criar uma oportunidade de encontro e aproximação de pessoas com e sem deficiência no campus da Praia Vermelha / UFRJ. O método de DanceAbility promove oficinas e workshops de dança e improvisação que criam condições para a problematização de concepções negativas da deficiência, baseadas eminentemente na falta e na incapacidade, bem como trabalhar artisticamente e eliminar barreiras existentes entre pessoas com e sem deficiência (LIBERMAN e SAMEA, 1998).

A oficina realizada na UFRJ teve três momentos: uma breve apresentação dos participantes, uma sequência de exercícios de contato corporal utilizando diferentes tipos de toque e também sons (proposições baseadas em elementos da natureza, movimentos fluidos em duplas, trios e grupos maiores) e uma roda final para troca de experiências. A atividade foi divulgada pelo Facebook, por email e por cartazes espalhados pelos Campi da UFRJ. Foi feito um convite especial aos participantes da Oficina de Corpo, Movimento e Expressão do Instituto Benjamin Constant. O grupo foi composto de 8 pessoas com deficiência (cegos, baixa visão, cadeirantes e deficientes intelectuais), entre alunos e convidados, e 22 pessoas sem deficiência (videntes, andantes). Os nomes que aparecem nos relatos foram escolhidos pelos próprios participantes, no momento da assinatura do Termo de Consentimento Livre e Esclarecido e do Termo de autorização para uso de imagem.

Um dos aspectos da formação dos estudantes de iniciação científica que participam do projeto é a escrita dos relatos cartográficos. Para produzir os diários de campo da pesquisa, eles são orientados a evitar a escrita abstrata, do tipo tradicional de relatório, que traz apenas informações objetivas e narrativas genéricas de situações. Ao contrário, são estimulados a exercitar uma escrita encarnada, escrevendo de dentro da experiência. A diferença entre escrita abstrata e escrita encarnada é inspirada nas distinção estabelecida por Pierre Vermersch (2000) entre fala abstrata e fala encarnada, no contexto da entrevista de explicitação. A escrita dos relatos cartográficos concorre para tornar a formação inventiva uma experiência corporificada e uma política 
cognitiva. Entendemos que as práticas de escrita dos diários de campo são também práticas de produção de si, de produção de subjetividade, na medida em que envolvem uma relação consigo e uma atenção a si. A escrita é uma espécie de fazer atento. Falamos então de um mecanismo de coemergência do diário de campo e do aprendiz (KASTRUP e GURGEL, 2019). Seguem alguns trechos dos diários de campo.

\section{a) Estranhamento}

Havia então chegado o dia do nosso primeiro Encontro Estético. Estava tudo combinado para que pudéssemos chegar com uma hora de antecedência na Praia Vermelha e montar o evento para começar a receber os inscritos. (...) Cheguei ao bar do Asterius com Amanda para nos encontrarmos com a Manoela como combinado, mas quem estava por lá era Manu. Ela batia um papo com Edna, uma das inscritas para participar do evento e que havia nos avisado numa ligação mais cedo que era deficiente visual. Por morar em Campo Grande preferiu sair de casa cedo para evitar que se atrasasse no caminho até a Zona Sul. Aquele encontro convocou em mim uma saída repentina da minha zona de conforto, do mundo vidente com o qual estou tão habituada e acomodada. Me deparei ali com um choque entre diferentes eficiências e deficiências o qual eu não estava esperando naquele momento e que escapou aо meu acervo de reações, produzindo um afeto. Me dei conta de que era o meu primeiro contato com uma pessoa cega em 24 anos vividos, um bocado de tempo no qual nunca me atentei para isso. De repente aconteceu. Cumprimentei tanto Manu quanto Edna apenas com um "oi" e acabei não me aproximando para um abraço ou beijo por um receio de que esse contato físico fosse incomodar ou ser invasivo a Edna de alguma forma. Ficamos por ali trocando algumas palavras $e$ enquanto ela falava percebi uma linguagem corporal e uma maneira de direcionar a fala e o corpo a mim com uma precisão impressionante à medida em que conversávamos. Seus movimentos com a cabeça e corpo tão bem direcionados a quem falava provocavam curiosidade. Senti como se ela estivesse me vendo por trás de seus óculos escuros. Por um segundo passou por meus pensamentos a ideia de que talvez eu estivesse me confundindo e ela não era cega, talvez tivesse escutado errado o que as meninas falaram. Mas depois que saí dali confirmei que não. Não havia feito confusão, ela era cega sim e me dei conta que estava, na minha cabeça, limitando sua possibilidade de movimentos por conta da cegueira (Lívia, estudante vidente).

Chama a atenção que, aos 24 anos, foi a primeira vez que a estudante teve contato direto com uma pessoa cega, mas parece trazer consigo uma certa imagem da pessoa cega marcada pela incapacidade, que dá lugar a uma sequência de experiências de estranhamento. Ela havia saído de longe para estar ali naquele encontro estético, revelava autonomia e um corpo desembaraçado. Talvez esperasse encontrar um corpo mais limitado, mais acanhado, menos vibrante. Observa, evita o beijo, talvez seja invasivo. Quais serão os códigos? Existe um código para nos aproximarmos de uma pessoa cega? Guarda certa distância. Por um instante, desconfia daquela cegueira. Estaria enxergando por trás dos óculos escuros? Curiosa e atenta à moça cega, que 
coloca em conflito suas ideias, se sente afetada por aquele encontro, onde experimentou um choque entre diferentes eficiências e deficiências.

\section{b) Surpresa}

Encontramos com Waldir em frente ao ponto de ônibus e fomos andando até a UFRJ, onde seria nosso evento. Ele era um senhor de seus 70 anos e no curto caminho que percorremos (do Instituto Benjamin Constant até a UFRJ), acabamos falando sobre várias coisas. Ele me perguntou se eu também era deficiente, eu respondi que em outras ordens, que tinha várias deficiências sim, mas enxergava. Ele riu. Nos contou que era taxista e com 50 anos perdeu a visão. (...) Quase chegando a UFRJ ele, que entrelaçou seus dedos em meu braço para que eu o ajudasse no caminho, pergunta: - "Esse passinho aí, devagar, é porque você anda assim mesmo ou é por minha causa? Porque se for, pode andar mais rápido! Esse momento foi muito interessante por me fazer perceber que eu, sem perguntar a ele em momento algum, supus que Waldir, por ser cego e por ser um senhor, precisaria de todo aquele cuidado para se locomover. Ele me explicou que se eu andar devagar, ele também anda e que eu deveria sempre andar um pouco a frente dele para guiar o caminho. Como eu o estava conduzindo, dava o compasso do nosso andar. Anotado (Mariana, estudante vidente).

Embora guiado pela estudante vidente, o homem cego assume o protagonismo. A estudante percebe que ele tem um saber sobre a sua cegueira, recebe o ensinamento e o encontro acaba por desconstruir a ideia de que deveria guiar aquela pessoa cega com uma atitude de superproteção.

Nos dois relatos, o encontro com pessoas cegas suscita experiências de problematização. A experiência de problematização se define por uma síntese disjuntiva entre o que se tem como saber e o que chega pelos sentidos, no momento presente. A situação presente não suscita reconhecimento, mas transborda o saber anterior. Também não é possível ignorar o que percebe. Problematiza: como assim? O saber anterior não se aplica aqui; ela é forçada a pensar. Como estranhamento ou surpresa, a experiência de problematização é o primeiro passo para aprendizagem inventiva (KASTRUP, 2007; KASTRUP, TEDESCO e PASSOS, 2008) e para a formação inventiva (DIAS, 2011; 2012).

Naqueles encontros, a problematização dá lugar a uma abertura da atenção ao outro e também de uma atenção a si. Há um momento de awareness, de dar-se conta, de tomar ciência. Não se trata de tomada de consciência no sentido da reflexão intelectual, sendo antes uma consciência perceptiva. A experiência remete ao que Antoine Hennion (2009) denomina reflexividade - aquela pequena parada na aprendizagem e na ação, em que ocorre um certo desmanchamento do eu e, simultaneamente, a possibilidade do objeto (ou de um outro) se desdobrar, se expressar, 
atualizar virtualidades, com pequenos gestos de abertura da atenção e possibilitando pequenas novas percepções.

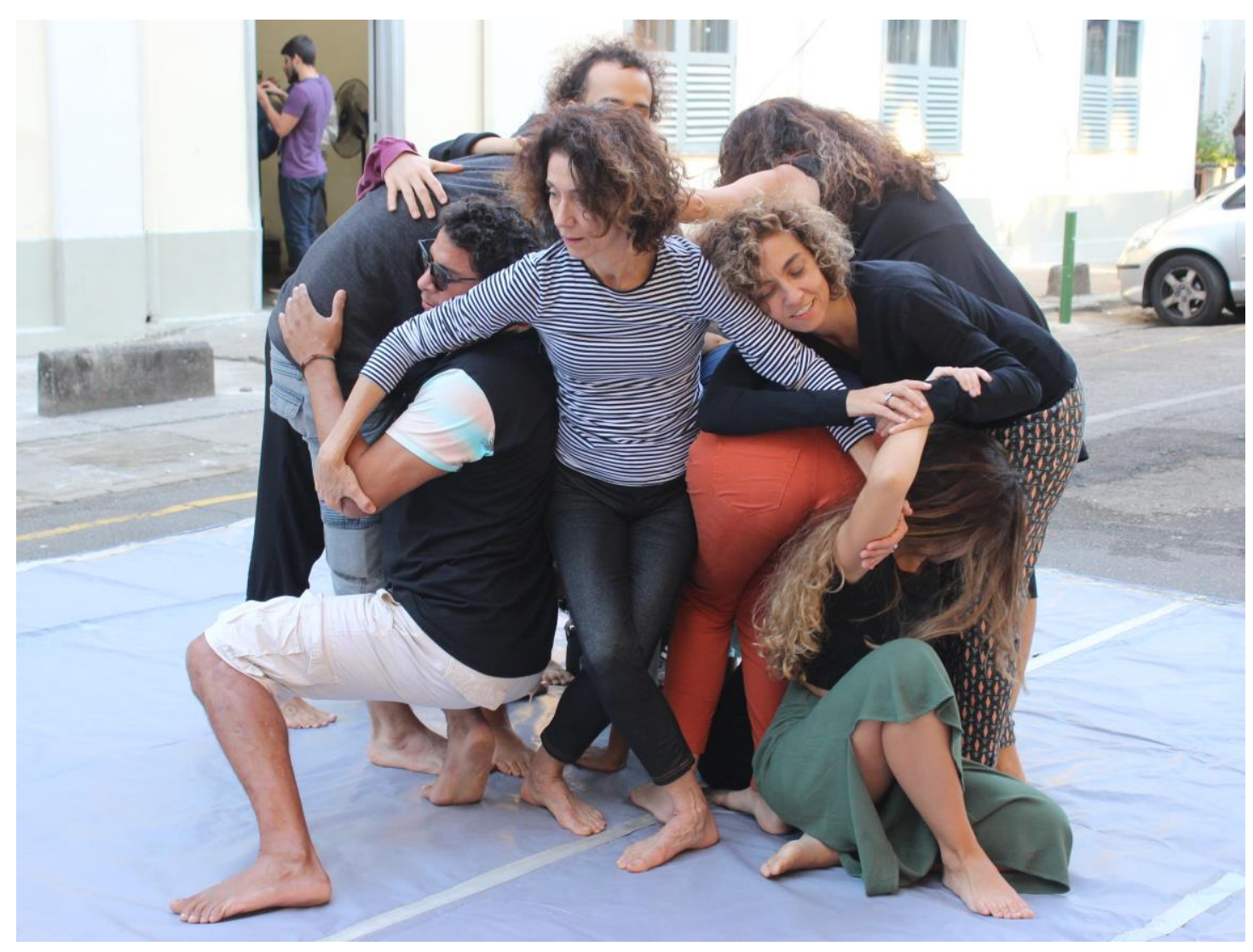

Oficina de DanceAbility

\section{c) Conexões}

No momento inicial da dança fiquei em um grupo composto por três pessoas, contando comigo. Uma delas era Mario, um colega de curso que é cadeirante. No início percebi que ele estava mais na dele, com a preocupação de que, se se entregasse à dança, machucaria alguém com suas rodinhas. (...) Ele se movimentava sempre com muita cautela e depois nos disse que faz muitos outros movimentos com a cadeira, que não havia se sentido confortável de fazer ali. (Mariana, estudante andante)

Sophia nos orientou para a próxima atividade. Era uma dança de olhos fechados em que o toque com seu par deveria se manter constante e fluido, trazendo uma ideia de dois corpos conectados. Uma terceira pessoa assumia o papel de anjo, protegendo aqueles movimentos, para que não houvesse choque entre as duplas. (...) Formamos uma dupla, eu e Edna, e nesse momento me vi em contato constante com o corpo de outra pessoa. A ideia era ficar de olhos fechados e isso me foi desconfortável, percebi uma certa resistência em manter meus olhos realmente fechados, como se procurasse controlar de alguma forma aquele momento através da visão. Foi interessante também que a Edna, que já tinha contato com a dança, tomou uma postura que me 
envolvia e guiava; puxava movimentos que eram mais ousados. (Amanda, estudante vidente)

Em seguida elaboramos uma dança naquela mesma intenção de conexão, agora acrescida de pausas e poses que fugiam às posições naturais rotineiras. Esta foi se desenvolvendo a partir do encontro e fusão dos grupos. Começamos em três e, conforme Sophia indicava, nos juntamos em 6, 9, 12... A dança crescia, até que nos unificamos num grande amontoado, ainda com muita harmonia e fluidez; éramos um grande rizoma embaralhado. Ali se corporificou toda a experiência. Compartilhamos, sem verbalizar, sensações e sentimentos: confiança, entrega, conexão. (...) Estávamos confortáveis. Era como se nos conhecêssemos há tempo; houve uma facilidade naquele encontro, que se concretizou nesse último momento. Ali tocamos e fomos tocados. (Amanda, estudante andante)

A oficina fez com que os estudantes exercitassem a conexão de olhos fechados, o uso do toque, o contato de corpos e a fluidez de movimentos. Um estudante cadeirante se mostra cuidadoso com os colegas e a moça cega faz movimentos ousados. A estudante relata uma experiência de facilidade, confiança e intimidade com os participantes com deficiência. Como todas as proposições podiam ser realizadas por todos os participantes, a oficina rompe, na prática, com o postulado da corponormatividade e trabalha sem hierarquia. A competência não está em jogo, não faz parte do jogo, e tampouco o padrão e a competição. Não há movimento certo e errado nem avaliação de resultados pela professora. Não há campo de visibilidade para a hierarquia capazes-incapazes.

\section{Um trabalho com os sentidos}

O projeto de pesquisa-intervenção Aspectos cognitivos da Orientação $e$ Mobilidade em pessoas com deficiência visual: em busca do movimento sensível e vital (Capes/FAPERJ) visa desenvolver conhecimentos e estratégias de intervenção articulando corpo, psicologia cognitiva e deficiência visual. Diversos autores consideram que a maior dificuldade para uma pessoa cega é deslocar-se no espaço intencionalmente, indo da posição em que se encontra para uma outra desejada. Tanto a pessoa com cegueira congênita quanto a que perdeu a visão em algum momento da vida e aquela com baixa visão encontram problemas de mobilidade. A cegueira produz efeitos sobre o desenvolvimento postural e motor em função da importância da visão na estabilização corporal, bem como na iniciação e no controle dos movimentos (HATWELL, 2003; VILLEY, 1914). Partindo dessas dificuldades, a Oficina Corpo, Movimento e Expressão acontece desde 2007 no Instituto Benjamin Constant (IBC) (POZZANA, 2008; 2010; 2017). A oficina ocorre uma vez por semana e o grupo tem 
em média 30 participantes. Estagiárias do curso de graduação em psicologia acompanham regularmente as aulas e produzem relatos cartográficos semanais.

Seguem alguns trechos de relatos de encontros das estagiárias com as pessoas com deficiência visual, marcados por surpresas, espantos, pela descoberta dos diferentes modos perceptivos e pelo trabalho sobre os sentidos, que ativam o corpo multissensorial das estudantes. Seguem mais alguns relatos que evidenciam a presença de experiências de problematização da política cognitiva capacitista.

Com esforço, consegui guiá-lo até uma cadeira, quando ele me pergunta: "Cadê Laura?" E eu respondo: "Tá ali". Uns segundos se passam até eu entender que só eu sabia dizer onde era o "ali". Dei-me conta da não familiaridade que eu tinha com pessoas não videntes e o mundo de coisas que eu ainda tinha a aprender daqui para frente". (Mayara, estudante vidente)

Laura disse para dançarmos livremente pela sala e foi isso que eu fiz. A música era animada, meio que um forró. Estava próxima do Eli, ele percebeu isso e me puxou para dançar junto. Ainda não sei como ele teve essa percepção, já que nada disse e porque ele não estava tocando minha mão. (Mayara, estudante vidente)

Ao darmos as mãos para estarmos em roda, seu Edson acabou com os meus ossinhos! Ele esmagou minha mão. Fiz cara feia, mas lembrei que precisava dar sinal sonoro para ele. Uma expressão facial não comunicaria meu desagrado. Saiu um "Ai, seu Edson!" (Mayara, estudante vidente)

Nos preparativos para a festa junina, houve um ensaio da quadrilha. Eles já estavam desde o início brincando e gritando 'Olha a cobra!' e 'Olha a chuva!'. Eu e minha irmã estávamos preocupadas e cheias de termos para evitarmos o verbo "olhar", mas quando percebemos que eles mesmos falavam desse jeito, a preocupação foi embora. Percebi que muitos problemas são mais nossos do que deles (Mayara, estudante vidente) 


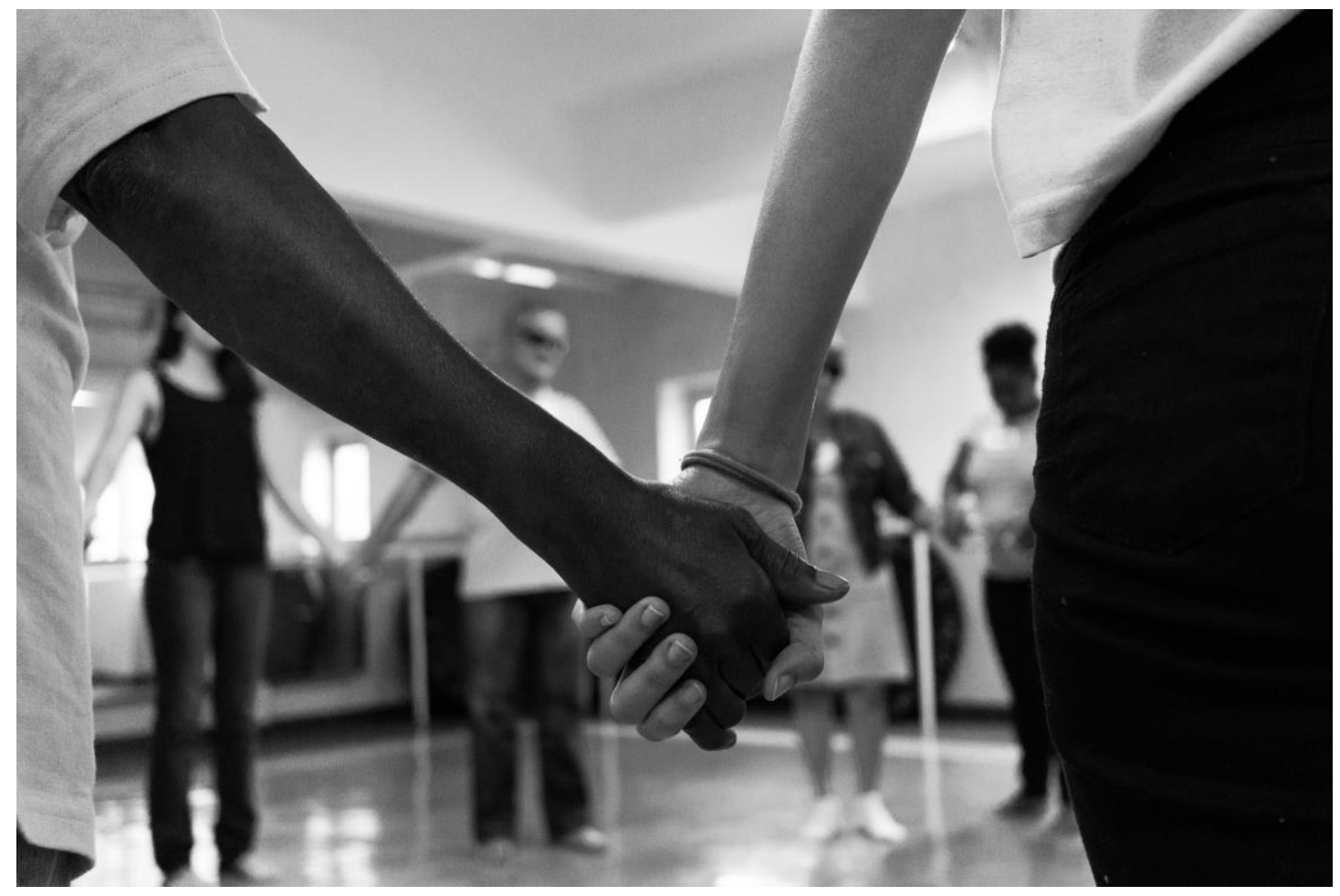

Oficina de Corpo, Movimento e Expressão

Chegamos e os participantes estavam na barra se alongando. Laura colocou uma música da Beth Carvalho, que havia falecido no dia anterior. Todos cantaram juntos. Laura convocou uma chamada-chamado - um modo criado na oficina de chamarmos por nós em voz alta e nos anunciarmos presentes na roda para quem não pode ver (POZZANA, 2017). Antes de falarmos nossos nomes ficamos um tempo em silêncio. Eu tive a impressão que esse início com a música da Beth Carvalho já tinha um significado, tanto pra Laura, tanto pra eles. Nesse momento de silêncio, tive a impressão que a Laura estava "mexida", talvez em luto. Pode ter sido só uma impressão, mas eu a tive. Laura começou um trabalho de busca de presença pedindo para sentirmos o chão, o apoio, os joelhos, o ventre (como um bambolê), os pulsos, os cotovelos, as axilas, a face, as articulações. Enquanto a Laura fazia os movimentos, eu a observei. Ela escuta a música, ela faz junto, ela sente a música e propõe o que ela está sentindo. Pensei que talvez eu tenha que fazer assim numa próxima oportunidade de conduzir a oficina com as meninas. Não é só ter mais calma nas propostas. É sentir a música, a roda e o que o meu corpo e talvez o que os corpos deles estão precisando (Maryssol, estudante vidente)

Aprendi com a condução da Laura a não ter pressa, a olhar o grupo, o que está acontecendo, sentir o que estamos propondo e não só propor. É preciso construir recursos e uma sintonia com os participantes para aprender como guiar movimentos de pessoas cegas. (Maryssol, estudante vidente)

O estágio na Oficina de Corpo, Movimento e Expressão é uma prática de formação inventiva em psicologia, na medida em que procura promover a abertura da atenção para a percepção do grupo e daquilo que está acontecendo, enquanto acontece. O que é melhor fazer? É melhor seguir a aula planejada? O cronograma? Será que tá 
funcionando? O que está surgindo de interessante no processo? O que chama atenção, não apenas do ponto de vista visual? Observando e atuando, o estágio suscita a atenção ao presente e o desejo de experimentar e criar ao trabalhar com pessoas cegas.

\section{O corpo aprendiz}

O projeto de extensão Acessando Uns aos Outros (UFRJ) tem como objetivo dar visibilidade à presença de alunos com deficiência no Campus da Praia Vermelha, contribuindo para construir uma política de acessibilidade baseada na reciprocidade e construção coletiva. Um dos Encontros Estéticos consistiu numa Oficina de Sensibilização com a Companhia Pulsar de Dança, realizada no Campus da Praia Vermelha. A oficina foi concebida e coordenada pelo bailarino Rogério Andreolli que, juntamente com os estudantes do projeto, definiram um circuito a ser percorrido com cadeiras de rodas e vendas. A ideia era criar condições para que alunos, professores, funcionários e pessoas que circulavam no campus pudessem ter a experiência corporal concreta dos obstáculos e barreiras para o deslocamento no campus. Foi feita uma ampla divulgação da Oficina nas diferentes Unidades da Praia Vermelha e os alunos com deficiência receberam convite especial para participar.

O circuito seria realizado em duplas ou trios (podendo haver a participação de alunos com deficiência) e, sempre que possível, haveria alternância de papeis na ida e na volta. O circuito tinha início em frente ao Instituto de Psicologia (IP) e ia até o bandejão. Na volta, passava pelo bar e quiosques de alimentação, onde o participante deveria comprar algo num dos trailers e retornar ao IP. O circuito incluía uma rua de paralelepípedos, uma rampa inacabada para acesso ao bar e um trailer com os produtos no alto.

\section{Caminhando com vendas}

Fui inicialmente acompanhando uma moça vidente, da qual não me recordo o nome. Antes dos primeiros passos, ela recapitulou mentalmente o caminho que faríamos, como se quisesse ter maior consciência do que estaria a vir. Logo à frente, admitiu haver perdido o controle do percurso. Vagarosa e atenciosamente fizemos o percurso, ela a todo tempo com apoio no meu braço ou ombro, com passos curtos, que as vezes apalpavam o chão antes de pisá-lo. Cria-se uma rápida relação de confiança com um desconhecido. A fim de quebrar o gelo, puxei conversa em certos momentos; a moça relatou que a voz a ajudava na orientação. Chegamos ao bandejão e trocamos as posições. Agora eu estava vendada e optei, por sugestão de Lívia, a andar sem auxílio, mas fui reorientada por minha parceira várias vezes durante o trajeto. Além da insistência em caminhar em diagonal - esquerda ou direita - foi constante meu estado de alerta corporal: meus braços estavam a todo momento 
como apoio pronto, para o caso de queda ou colisão. A sensação de passar entre outras pessoas desnorteava, as vozes e passos pareciam muito mais próximos do que realmente o eram. Primeira experimentação feita". (Amanda, estudante vidente)

A venda desloca a hegemonia da visão, que permite a antecipação dos obstáculos no caminho e dá a sensação de controle da situação. Ao mesmo tempo, a ausência da visão desperta outros sentidos: o pé vira uma superfície tátil, ouve passos. A atenção entra no modo de alerta corporal: os passos são curtos e os braços ficam enrijecidos, como que apoiados no ar, antecipando a queda iminente. Caminhar com vendas cria condições para uma breve experiência da deficiência visual. Experiência que, sempre devemos lembrar, é apenas passageira e momentânea, pois ao final as vendas serão retiradas. Sempre devemos ressaltar isso quando propomos uma oficina dessa natureza. 


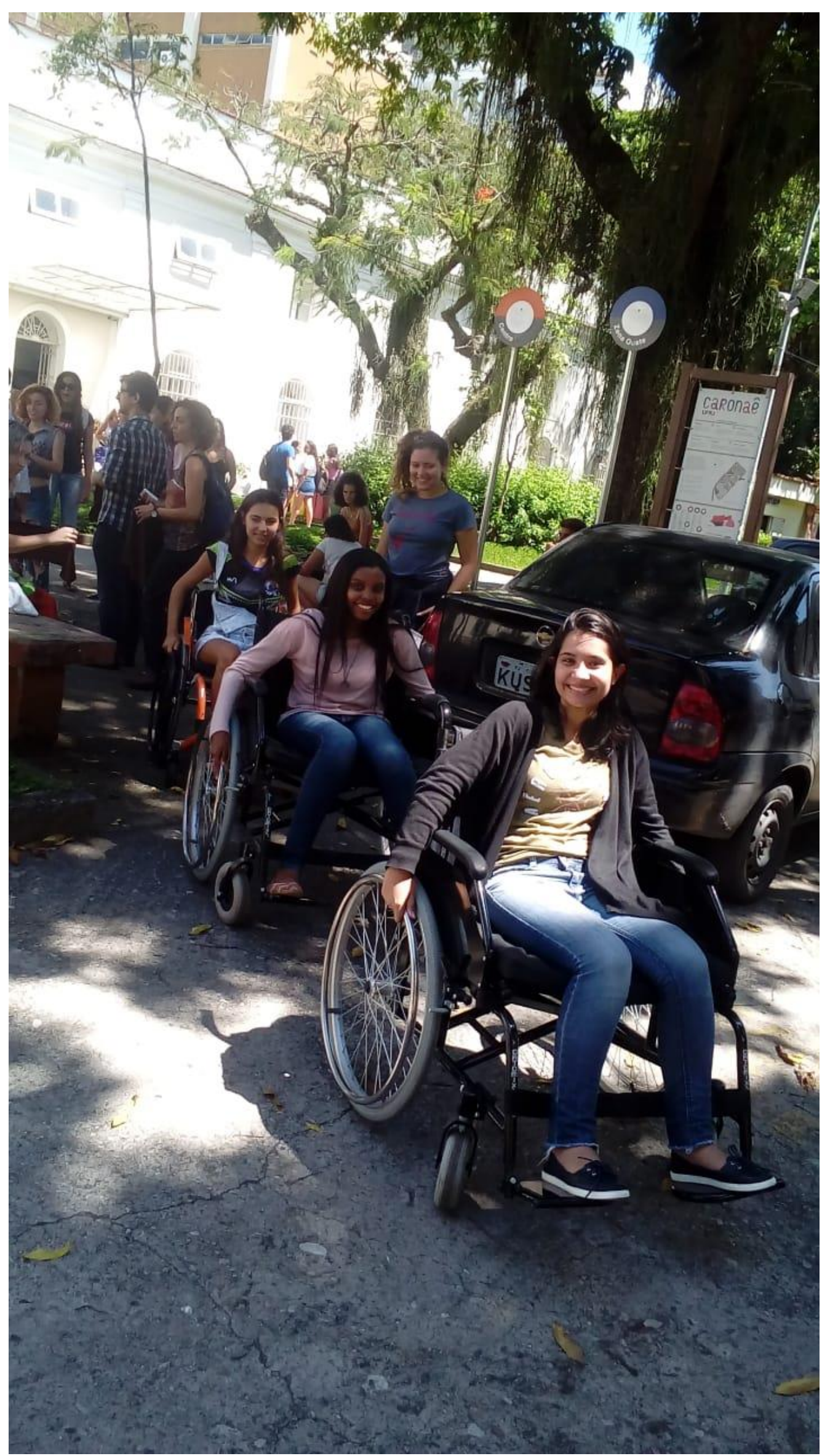




\section{Oficina de Sensibilização}

\section{A cadeira de rodas e o problema do ponto de vista}

Seguimos nosso caminho na cadeira de rodas, até chegar na área de alimentação, me trazendo a sensação da qual o Rogério falou: não ter a visão completa de tudo que estava disposto nos trailers. Nesse momento eu percebi como meu campo de visão havia mudado e como minha percepção do espaço mudava, onde meu olhar atingia. Esta parte foi a que mais me impactou de todo o percurso. Assim que cheguei novamente ao local de partida, o grupo perguntou como foi, falei sobre isso. O fato de eu ser alto, me permite ter uma certa visão privilegiada sobre alguns espaços e este privilégio me foi retirado assim que eu sentei na cadeira de rodas. Minha perspectiva mudou completamente (Ítalo, estudante andante).

O estudante tinha a informação da dificuldade de ter acesso aos produtos expostos no trailers, mas sentado na cadeira ela fez sentido de uma outra maneira. Seu corpo experimenta. $\mathrm{O}$ rapaz fala de um privilégio que havia perdido naquele momento e de uma mudança de perspectiva ${ }^{1}$.

Pensando com Donna Haraway (1995), consideramos que não basta mostrar que existem pontos de vista distintos de uma mesma realidade preexistente, de um mesmo mundo. Mais do que isso, é preciso buscar um entendimento do mundo que contemple a multiplicidade de pontos de vista e de modos de vida. Com a oficina, experimentamos uma concepção corpórea da visão, distinta da visão distanciada, de lugar nenhum. $\mathrm{O}$ conceito de ponto de vista dá conta dessa visão sempre situada e a oficina de sensibilização cria condições de possibilidade para uma experiência momentânea da deficiência, mas que vai além da vivência pessoal. Não se trata de troca de papeis, mas de experimentar a percepção situada por meio da tensão e do contraste. No caso do estudante andante, que naquele dia circula no campus numa cadeira de rodas, a tensão e o contraste das duas perspectivas o leva a dar-se conta de que sua posição de quem caminha com os próprios pés é um privilégio e uma perspectiva, e não uma posição natural, abstrata e desencarnada, de lugar nenhum. Todo conhecimento é localizado e parcial, e isso vale para o andante e para o cadeirante. Ao sentar-se na cadeira de rodas, o olho situado no corpo alto desaparece; ao levantar-se da cadeira, é o ponto de vista do cadeirante que é desmanchado. Na oscilação dos pontos de vista, entre um e outro, um mundo mais diverso e heterogêneo pode advir.

\section{Um corte, um desconforto e a dimensão ético-política}

(Na rua de paralelepípedos) a sensação de ser empurrada (na cadeira de rodas) com o corpo inclinado para trás me trazia arrepios, eu soltava pequenos gritos 
constrangedores, gargalhava mais um bocado. Passados os paralelepípedos, assumi o controle da cadeira e não demorou para sentir meus braços moídos. $O$ riso e as brincadeiras nos acompanhavam. Em frente ao Instituto de Psiquiatria (IPUB) havia um senhor de cadeira de rodas. Negro, sem uma perna, com a feição fechada. Não era um participante da Oficina de Sensibilização. A experimentação se reconfigurou, minha vivência descontraída passou a incomodar. Como aquele senhor se sentia com nossa (pessoas sem deficiência, ao menos assim categorizadas) presença sorridente e expansiva em uma cadeira de rodas? Imaginava tamanho desrespeito poderia ser aquele (Amanda, estudante andante).

O encontro foi narrado também pelo condutor da cadeira.

Na ida para o bandejão perto do IPUB, notei um homem que não tinha uma das pernas e também estava sentando em uma cadeira de rodas. Na hora me questionei se nossa atividade poderia soar ofensiva para ele. Afinal, duas pessoas sem nenhuma lesão motora estavam fazendo uso do mesmo instrumento de locomoção dele, porém encarando os desafios de usá-lo com muito humor. Ele encarou a cena com um olhar fixo e sério, e fiquei um pouco desconfortável, mas segui o nosso percurso (Ítalo, estudante andante).

A experiência corporal de ser empurrada numa cadeira de rodas era inusitada e, entre o medo de cair e certeza de que logo terminaria aquela situação, a oficina era vivida quase como uma brincadeira. Em algum nível e em alguma medida havia a experiência corporal da deficiência. Por exemplo, a fadiga podia fazer pensar que deve ser cansativo para um cadeirante conduzir sua própria de cadeira de rodas. Mas logo terminaria aquela dificuldade e eles voltariam à condição de andantes. $\mathrm{O}$ encontro dos dois estudantes com o senhor negro, sem uma perna, numa cadeira de rodas, com uma lesão evidente, provoca um susto, uma espécie de choque de realidade. Era bem diferente daquela experiência passageira, temporária, tensa, mas por vezes até divertida. Em mais uma experiência de problematização, o encontro com aquele homem negro e de olhar sério demonstra que a formação inventiva tem uma dimensão ético-política. A oficina de sensibilização não visa mudar uma ideia ou uma crença, fornecendo novas informações. O que está em jogo é o corpo-aprendiz, as mudanças de ponto de vista, de perspectiva, a partir de experiências situadas, corporificadas, concretas. A aposta é na desnaturalização do ponto de vista de estudante sem deficiência, onde o capacitismo habita de maneira clandestina.

\section{Deslocando o capacitismo em oficinas de formação inventiva}

O capacitismo, ainda presente no dia a dia da universidade, marca a convivência de alunos com e sem deficiência. Não se trata de um punhado de ideias abstratas e de falsas crenças acerca da inferioridade e da incapacidade dos colegas com deficiência. 
Trata-se de uma política cognitiva bem anterior ao ingresso na universidade, mas que pode ser acirrada quando a formação é, ela mesma, capacitista. Para minimizar as práticas de opressão e mudar este cenário, não basta aumentar a quantidade de informação e inserir teorias sobre a deficiência na formação do psicólogo. Ainda que tais iniciativas sejam importantes e bem vindas.

Neste estudo, apontamos a importância de discutirmos modos de ensinar e estratégias de formação, apontando a fecundidade das oficinas de formação inventiva. Entendemos que a participação de estudantes em oficinas que mobilizam experiências artísticas e práticas corporais, realizadas no contex to de projetos de pesquisa e extensão, permitem a habitação de um território comum e encontros de alunos e pessoas com deficiência. Os encontros problematizam o capacitismo, buscando desconstruir barreiras e desigualdades. Com práticas que promovem a ativação de experiências multissensoriais e a mobilização do corpo aprendiz, encontramos indícios de possíveis deslocamentos na política cognitiva capacitista nos estudantes.

Um ponto de destaque foi a abertura da atenção dos estudantes durante as práticas, que passa a ser tocada pelas eficiências e potências inesperadas das pessoas com deficiência. As oficinas criam outras formas de convivência e de composição, bem como outras formas de intimidade. Abrem-se frestas para a curiosidade, que é indispensável à invenção. A atenção é capturada, ensaiando processos de atenção conjunta. Dar atenção ao que pode o corpo de uma pessoa com deficiência é também reconhecê-las como dignas de interesse enquanto pessoas singulares. É um modo de declarar sua importância, bem como a de seus corpos diversos e seus diferentes modos de conhecer e estar no mundo. As oficinas visam exercitar e propiciar a aprendizagem desses modos de atenção conjunta. A atenção a si e o encontro com a alteridade que nos habita - onde se esconde o capacitismo - também é parte da formação inventiva.

Com a participação de alunos em tais projetos e nas oficinas, buscamos concorrer para uma formação em psicologia comprometida com a dimensão ética e política da invenção de si e do mundo. Para terminar, lembramos Eduardo Viveiros de Castro (2015), quando ele afirma que, se a antropologia possui uma tarefa, ela não é conhecer o mundo do outro, mas multiplicar os mundos. Para nós, a presença dos alunos com deficiência na universidade, e em particular no curso de psicologia, não nos coloca apenas a tarefa de difundir o conhecimento sobre a deficiência, mas nos dá a preciosa oportunidade de multiplicar nossas maneiras de ser, de sentir e de conhecer em prol de um mundo mais diverso, que nos honraremos em habitar. 


\section{Referências}

DELEUZE, Gilles e GUATTARI, Félix. Mil Platôs. Capitalismo e esquizofrenia, v.1. Rio de Janeiro: Ed. 34, 1995.

DIAS, Rosimeri de Oliveira. Deslocamentos na formação de professores: aprendizagem de adultos, experiência e política cognitiva. Rio de Janeiro: Lamparina, 2011.

DIAS, Rosimeri de Oliveira (org.). Formação inventiva de professores. Rio de Janeiro: Lamparina, 2012.

HARAWAY, Donna. Saberes localizados: a questão da ciência para o feminismo eo o privilégio da perspectiva parcial. Cadernos Pagu, 5, 1995, p.07-41

HATWELL, Yvette. Psychologie cognitive de la cécité precoce. Paris: Dunod, 2003.

HENNION, Antoine. Reflexivités: l'activité de l'amateur. Reseaux 2009, n. 153, p. 55 78.

KASTRUP, Virgínia. A invenção de si e do mundo: uma introdução do tempo e do coletivo no estudo da cognição. Belo Horizonte: Autêntica, 2007.

KASTRUP, Virgínia. Cegueira e Invenção. Cognição, arte, pesquisa e acessibilidade. Curitiba: CRV, 2018.

KASTRUP, Virgínia, TEDESCO, Silvia e PASSOS, Eduardo. Políticas da cognição. Porto Alegre: Sulina, 2008.

KASTRUP, Virgínia e GURGEL, Verônica. O papel da escrita na formação de professores e o problema da coemergência. Em: DIAS, Rosimeri de Oliveira e RODRIGUES, Heliana de Barros Conde (orgs) Escritas de si. Rio de Janeiro: Lamparina, 2019. p.60-71.

LIBERMAN, Flávia e SAMEA, Marisa. Uma pesquisa do corpo em terapia ocupacional: o método de Danceability. Revista de Terapia ocupacional. USP, v.9, n.3,p125-132, set. / dez., 1998.

MELLO, Anahí Guedes de. Deficiência, incapacidade e vulnerabilidade: do capacitismo ou a preeminência capacitista e biomédica do Comitê de ética em Pesquisa da UFSC. Ciência e saúde coletiva, v.21 n.10, 2016, p. 3265-3276.

PASSOS, Eduardo, KASTRUP, Virgínia e ESCOSSIA, Liliana. (orgs) .Pistas do Método da Cartografia. Pesquisa-intervenção e produção de subjetividade. Porto Alegre: Sulina, 2009.

PASSOS, Eduardo, KASTRUP, Virgínia e TEDESCO, Silvia. (Orgs.) Pistas do Método da Cartografia. A experiência da pesquisa e o plano comum. Porto Alegre: Sulina, 2014.

POZZANA, Laura. O Corpo em conexão. Niterói: Editora da UFF, 2008.

POZZANA, Laura. Oficina de Movimento e Expressão com deficientes visuais: uma aprendizagem coletiva. Em: MORAES, Marcia e KASTRUP, Virgínia (orgs). Exercícios de ver e não ver: arte e pesquisa com pessoas com deficiência visual. Rio de Janeiro: Nau, p. 76-95, 2010. 
POZZANA, L. Corpo e cegueira: movimento sensível e vital. Curitiba, CRV, 2017.

POZZANA, Laura e KASTRUP, Virgínia. A roda como método de aprendizado do movimento com pessoas com deficiência visual: O papel dos relatos de campo na pesquisa-intervenção. Revista Benjamin Constant. 58, 2, 2015, p.134-150.

POZZANA, Laura e KASTRUP, Virgínia. Formação em psicologia e saúde mental na atualidade: uma oficina de corpo e um caderno coletivo como dispositivos experimentais. Mnemosine. 15, 1, 2019, p.89-114.

ROLNIK, Suely. Cartografia sentimental. Porto Alegre: Sulina, 2006.

VERINE, Bertrand. À la recherche du point de vue aveugle. Em: R. Dutry \& B. de Patou (eds.). La Peinture dans le noir: contributions à une théorie du partage des sensibles, Voir barré, 34-35, 2007, p.99-115.

VERINE, Bertrand. Não podemos ver, não podemos tocar: quais as repercussões dessa máxima no discurso das pessoas cegas? Revista Benjamin Constant, v.19, Edição Especial, 2013, p.6-19.

VERMERSH, Pierre. L'entretien d'explicitation. Issy-les-Molineaux: ESF, 2000.

VILLEY, Pierre. Le Monde des Aveugles - essay de psychologie.Paris: Flammarion, 1914.

VIVEIROS de CASTRO, Eduardo. Metafísicas Canibais - elementos para uma antropologia pós-estrutural. São Paulo: Cosac \& Naify, 2015.

\section{Virgínia Kastrup \\ Professora Titular do Instituto de Psicologia Programa de Pós-Graduação em Psicologia da UFRJ (Bolsa PQ CNPq) \\ E-mail: virginia.kastrup@gmail.com}

Laura Pozzana Pós-doutoranda no Programa de Pós-Graduação em Psicologia da UFRJ. (Bolsa

FAPERJ/CAPES)

E-mail: laura.pozzana@gmail.com

\footnotetext{
${ }^{1} \mathrm{O}$ conceito de ponto de vista tem uma longa história. Ele ocupa lugar de destaque na teoria feminista (feminist standpoint), na teoria racial crítica e no pensamento decolonial. O conceito de ponto de vista não equivale a uma experiência individual, mas aquela de grupos subalternizados, em que a visibilidade da produção intelectual, os saberes e narrativas precisam ganhar espaço. Visa também criticar posições e conhecimentos supostamente universais e abstratos. Trata-se da afirmação do lugar de onde se vê, se conhece e se fala. No campo dos estudos da linguagem, o linguista cego Bertrand Verine $(2013 ; 2017)$ propõe o conceito de ponto de vista cego. Equivocando a relação entre o olhar e o ponto de vista, designa o lugar de percepção pelo qual passa todo enunciado. Verine aponta que a suposta dominância da visão aparece muitas vezes no discurso das próprias pessoas cegas.
} 